\title{
Fracture toughness of ice and firn determined from the modified ring test
}

\author{
Mark P. Fischer," Richard B. Alley, \\ Department of Geosciences and Earth System Science Center. The Pennsylvania State University, University Park, \\ Pennsylvania 16802-7501, U.S.A. \\ TERRY ENGELDER \\ Department of Geosciences, The Pennsylvania State University, University Park, Pennsylvania 16802-7501, U.S.A.
}

\begin{abstract}
The modified ring test is used to determine the fracture toughness of synthetic, granular, fresh-water ice (average density $0.891 \mathrm{Mg} \mathrm{m}^{3}$ ) and firn (average density $0.605 \mathrm{Mg} \mathrm{m}^{-3}$ ) from depths between 26 and $27.2 \mathrm{~m}$ in the $\mathrm{E}$ core of the Greenland Ice Sheet Project II. Average fracture toughness is $145.7 \mathrm{kPa} \mathrm{m}^{\frac{2}{2}}$ for the manufactured ice and $108.6 \mathrm{kPa} \mathrm{m}^{\frac{1}{2}}$ for the firn. Comparison between the ice and firn suggests that ice-fracture toughness decreases with decreasing density (i.e. increasing porosity), suggesting lateral and vertical variations in the near-surface fracture resistance of glaciers and ice sheets may be related to firn densification. The modified ring test has many advantages over conventional, notch-based specimens in that complications which arise in notched specimens due to crack-length, loading-rate, notch-acuity and specimen-size effects are irrelevant for a modified ring-specimen geometry.
\end{abstract}

\section{INTRODUCTION}

Linear elastic-fracture mechanics (LEFM) is a branch of continuum mechanics which analyzes material failure through the initiation and propagation of sharp flaws i.e. cracks) in a material. A fundamental parameter in LEFM is the crack-tip stress-intensity factor, $K_{\mathrm{I}}$, which under conditions of plane strain is given by

$$
K_{\mathrm{I}}=Y \sigma \sqrt{\pi c}
$$

where $\sigma$ is the applied crack-normal tension, $Y$ and $c$ are parameters respectively characterizing the shape and size of the crack, and the subscript I denotes the application of crack-normal tension (i.e. mode I loading; Broek, 1986). For materials that do not exhibit $R$-curve behavior Broek, 1986), the onset of rapid crack growth occurs when the stress intensity at the tip of the crack reaches some critical value, $K_{\text {Ic }}$, commonly referred to as the plane-strain fracture toughness. Use of $K_{\mathrm{lc}}$ as a measure of rock-fracture strength implicitly assumes that continuum mechanics applies and that any region of inelastic deformation near the crack tip (i.e. process zone) is small in comparison with other

\footnotetext{
* Present address: EXXON Production Research Company, P.O. Box 2189, Houston, Texas 77252 2189, U.S.A.
}

characteristic dimensions of the body (e.g. crack length, specimen dimensions; Ingraffea, 1987).

The use of LEFM to analyze crack initiation in ice is well established (e.g. Miller, 1984) and much of the past work on ice fracture concentrated on measuring the fracture toughness of ice (e.g. Goodman and Tabor, 1978; Liu and Miller, 1979; Nixon and Schulson, 1986; Parsons and Snellen, 1986). More recent work on the fracture toughness of ice has concentrated on the standardization of testing techniques and the characterization of experimental variables in fracture-toughness testing. As noted by Dempsey and others (1989a), many earlier investigations of ice-fracture toughness were hindered by experimental difficulties, resulting in unreliable data. Consequently, laboratory measurements of the fracture toughness of ice made prior to 1989 are often characterized by a wide scatter (e.g. Goodman and Tabor, 1978; Liu and Miller, 1979; Andrews and others, 1984; Danilenko, 1985; Nixon and Schulson, 1987). This scatter is thought to reflect the influence of various testing parameters on experimentally determined values of fracture toughness (Dempsey and others, 1989a,b). Standardization of testing techniques and characterization of experimental variables by Dempsey and others (1989a, b) has recently resulted in more consistent data. However, test methods currently employed are timeconsuming and somewhat tedious in that a careful record of each influential testing parameter (e.g. temperature, loading rate, time between machining and testing) must be maintained. 
In this paper we present results from fracturetoughness testing of ice and firn using a recently developed modified ring-testing method (Thiercelin and Roegiers, 1987). The purpose of this work is to provide a first-order constraint on the fracture toughness of firn and to introduce the modified ring test to the glaciological community. The utility of the MR test arises, because it does not appear to be influenced by many of the experimental parameters currently complicating fracture-toughness testing of ice. Because use of the modified ring-testing method is limited (to our knowledge the only published uses of it are in Thiercelin (1987), Thiercelin and Roegiers (1987), Thiercelin and others (1987), Thiercelin (1989)), we present an explanation of the technique and mention some of the parameters which might influence results obtained from it. Advantages of the modified ring test in comparison to notch-based test geometries are discussed.

\section{EXPERIMENTAL PROGEDURE}

The modified ring (MR) test first presented by Thiercelin and Roegiers (1987) and later utilized by Thiercelin $(1987,1989)$ is a variation of the well-known Brazilian test in which a cylinder is compressed across the diameter, resulting in longitudinal splitting of the specimen. For the MR test, two diameterically opposed, flat-loading surfaces are machined along the edges of a cylindrical specimen and a hole is drilled in the center of the cylinder (Fig. 1a). Compression applied to the loading surfaces initiates cracks at the top and bottom of the center hole which propagate parallel to the loading axis (Fig. 1b). In the MR test, loading across the opposing flat surfaces results in a zone of compressive crack-normal stress near the loading surfaces. This zone of compression reduces the size of the process zone at the tip of an approaching crack and thereby facilitates accurate LEFM testing of specimens that were previously considered sub-sized (Thiercelin and Roegiers, 1987).

The MR test requires a record of the time variation of compressive axial load during deformation of a specimen and a means to calculate numerically the stress-intensity factors in a model specimen with exactly the same geometry as the test specimen. A typical loading curve recorded during the MR test is shown schematically in Figure 2a. Axial load increases at a constant displacement rate until time $t_{0}$, when cracks initiate from the top and bottom of the central hole in the specimen. Between times $t_{0}$ and $t_{\mathrm{c}}$, the cracks propagate unstably, during which the axial load decreases from $\sigma_{\mathrm{i}}$ to $\sigma_{\mathrm{ac}}$ (Fig. 2b). The decrease in load coincident with crack growth occurs because relative to the ram-head displacement rate, crack propagation is essentially instantaneous, simulating a fixed-grips boundary condition (Lawn, 1993). As the cracks grow, the mode I stress-intensity factor at the tips of the cracks increases with crack length from time $t_{0}$ to $t_{\mathrm{c}}$ as shown in Figure 2c. After time $t_{c}$ interaction between the cracks and the crack-normal compressive stress field near the loading surfaces causes the mode I crack-tip stressintensity factors to decrease with increasing crack length (Fig. 2c). Thereafter, a continuously increasing load is required to drive the cracks (Fig. $2 \mathrm{a}, \mathrm{b}$ ). The maximum in

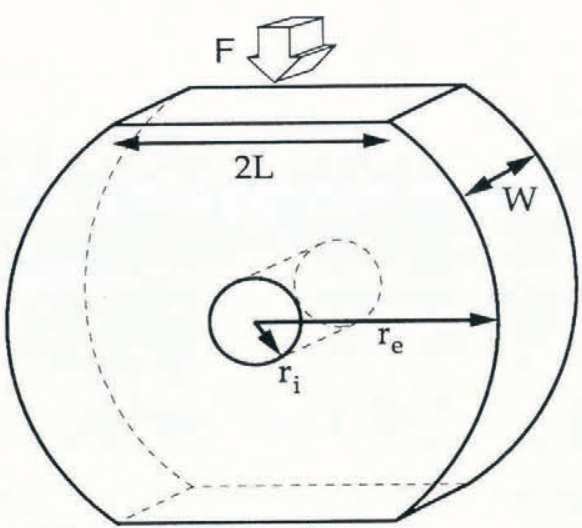

(a)

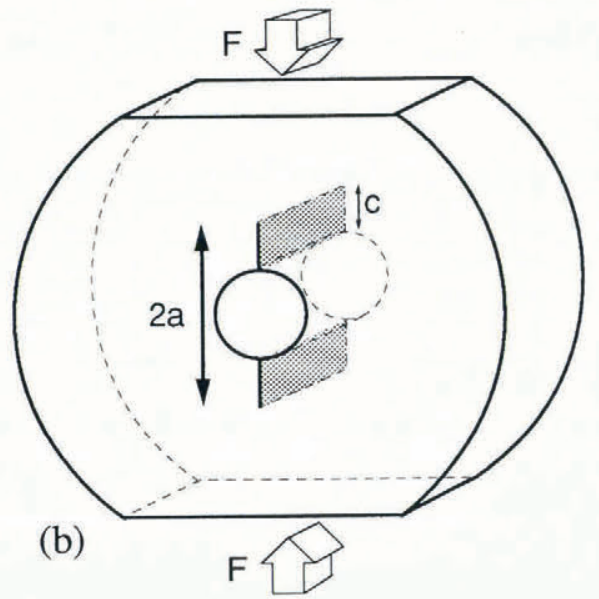

Fig. 1. Geometry of the modified ring-test specimen.

the $K_{\mathrm{I}}$ versus time curve $\left(K_{\operatorname{Imax}}\right)$ defines the fracture toughness $\left(K_{\mathrm{Ic}}\right)$ of the material, because it is this value of $K_{\mathrm{I}}$ that marks the transition from unstable to stable crack growth. Figure 3 shows load vs time and displacement vs time output collected during one of our tests.

The critical stress-intensity factor coincides with a minimum in the axial load recorded in the laboratory, which occurs when the cracks reach the critical length, $a_{\mathrm{c}}$. For crack lengths greater than or equal to $a_{c}$, the process zone is assured to be small in comparison with the crack length because of the influence of the crack-normal compression near the specimen loading surfaces (Thiercelin and Roegiers, 1987). Because the load minimum occurs at a critical crack length, use of the modified ring test eliminates the need for laboratory measurement of crack lengths in determining the unconfined fracture toughness of materials. One simply takes the value of the load minimum recorded during a test, applies that load to a sample in a numerical simulation and calculates a $K_{\mathrm{I}}$ versus the crack-length curve corresponding to that specimen geometry and load. The peak in the resulting curve is the fracture toughness of the tested material.

Two competing behaviors are important to consider when designing a MR specimen. Reliable results require a well-defined minimum in the load curve and a corresponding critical crack length that is sufficiently long to be resolved in the finite-element model. Accurate constraint 

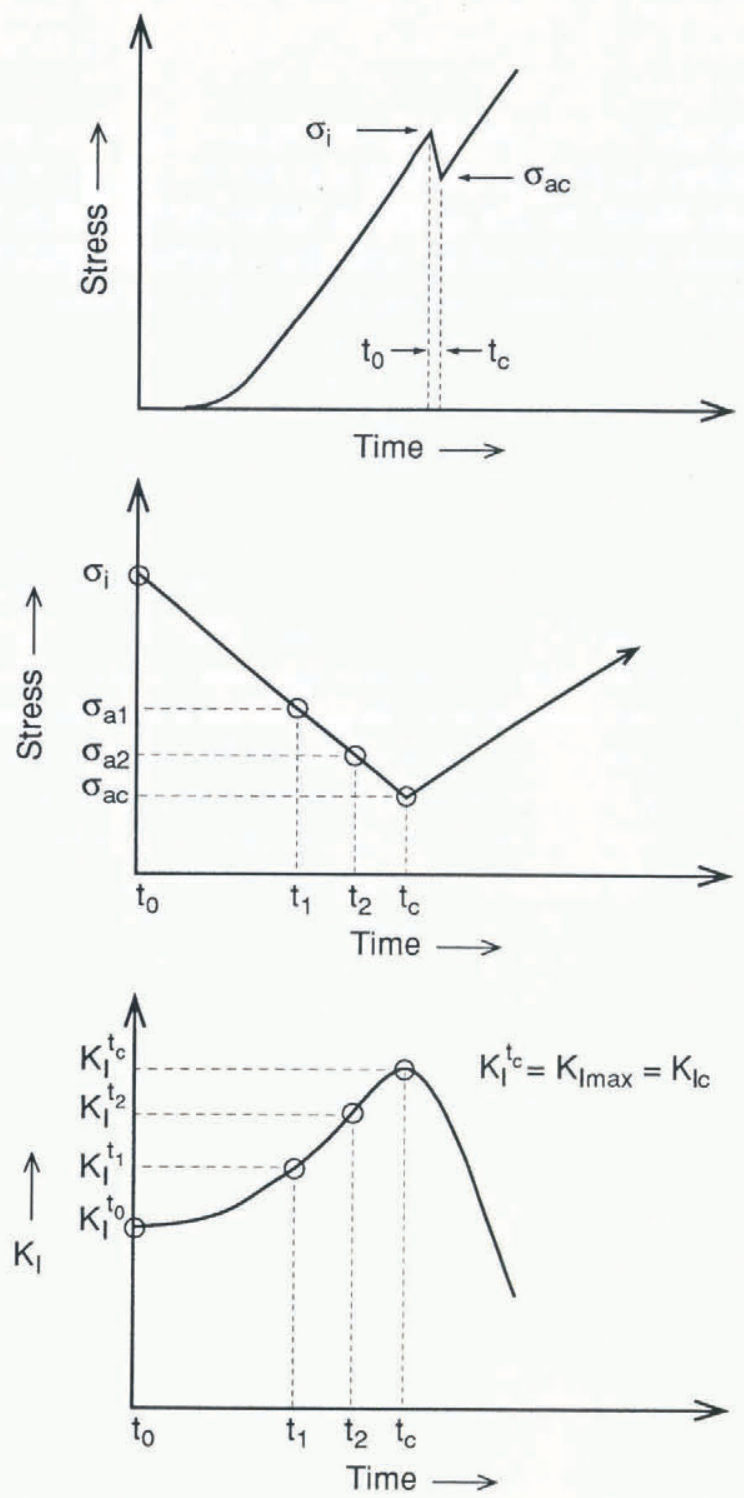

Fig. 2. Mechanics of the modified ring lest. (a) Typical time-varying record of applied stress during a modified ring test. (b) Variation in stress during crack growth in a modified ring specimen. Stress drop results from unstable crack propagation between times $t_{0}$ and $t_{\mathrm{c}}$. Stress increases after crack reaches a critical length, $a_{\mathrm{c}} .(c)$ Variation in $K_{\mathrm{I}}$ with time during a modified ring test. All plots are schematic.

on the $K_{\mathrm{I}}$ versus crack-length curve, and hence, $K_{\operatorname{Imax}}$ and $K_{\text {Ic }}$ determined from finite-element modeling is most easily attained with longer critical crack lengths. Longer critical crack lengths result when the length of the specimenloading surfaces is reduced. However, for specimens with short loading surfaces, there is a tendency for the cracks to propagate completely to the loading platens, resulting in a load curve with a poorly defined or absent load minimum. Several iterations of laboratory experiments and finiteelement modeling are commonly required to determine a specimen geometry that will produce both a well-defined load minimum and a critical crack length which is long enough to allow accurate resolution of $K_{\operatorname{Imax}}$ in the numerical model. The samples we used have appropriate dimensions for ice and firn.
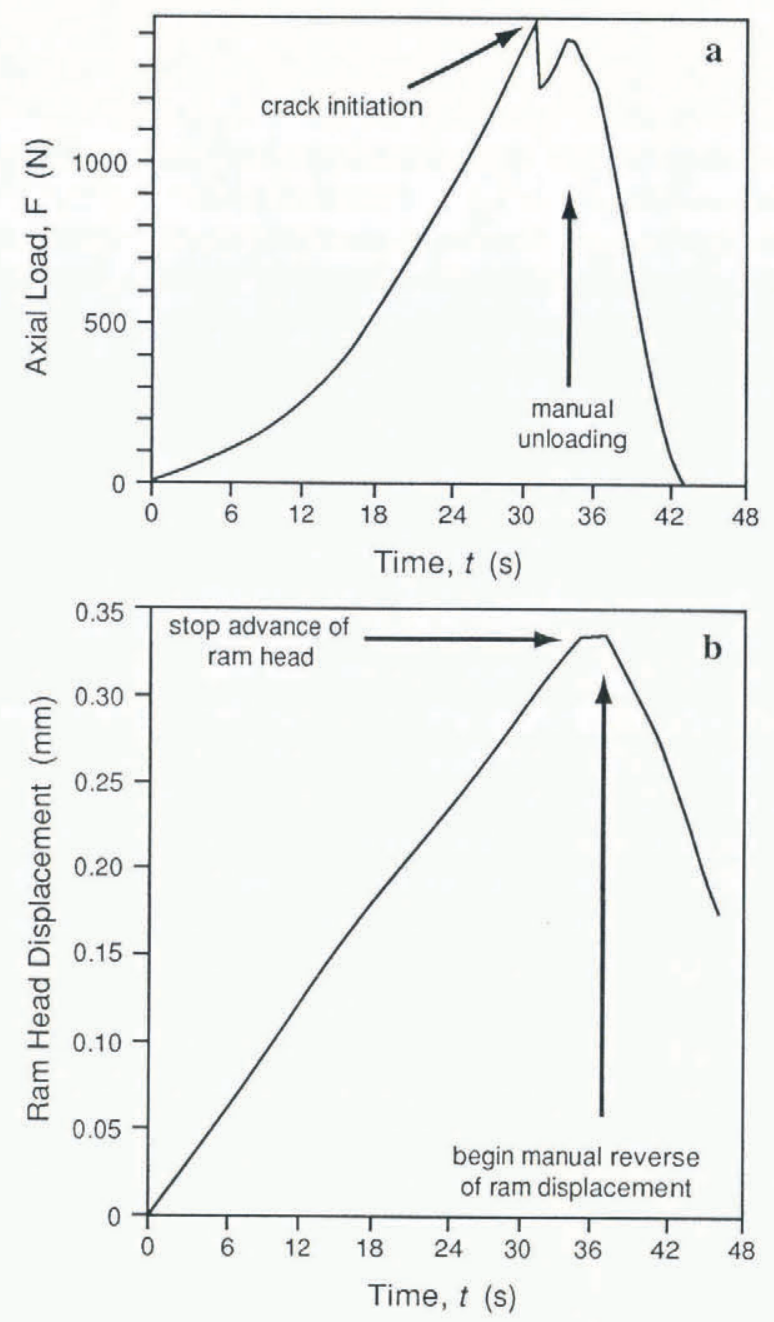

Fig. 3. Load (a) and displacement (b) vs time output from a modified ring test on firn specimen number 12 .

Note that the modified ring test measures $K_{\text {Ic }}$ by determining $K_{\mathrm{I}}$ at the tip of a propagating crack as it crosses the boundary from unstable to stable propagation (Fig. 2c). The crack does not stop propagating at the point where $K_{\mathrm{I}}=K_{\operatorname{lmax}}$ because the axial load on the sample is continuously increasing; crack growth continues because the axial load increases above $\sigma_{\mathrm{ac}}$ (Fig. 2). Although one would ideally like to halt the experiment exactly at $\sigma_{a c}$ and compare the observed crack lengths with the critical crack lengths observed in the numerical models, this is not possible because accurate definition of $\sigma_{\text {ac }}$ requires that the experiment be continued beyond this load level. In practice, one might be able to halt the experiment very near $\sigma_{\text {ac }}$ but such experiments would require a very stiff servo-controlled loading apparatus which was not available to us.

\section{Numerical modeling}

Because the modified ring test utilizes numerical modeling to determine fracture toughness, it is pertinent to discuss the details of the modeling procedure. In this study, numerical simulation was accomplished with the interactive finite-element program FRANC (FRacture ANalysis Code; Wawrzynek and Ingraffea, 1987) developed at Cornell University. This program simulates the $r^{-\frac{1}{2}}$ 
singularity in the crack-tip stress field, where $r$ is the radial distance away from the crack tip, by surrounding each crack tip with a rosette of eight, triangular, quadratic, isoparametric, quarter-point elements (e.g. Barsoum, 1976). The remainder of any model mesh is composed of quadratic, isoparametric elements. FRANC is particularly well-suited for analyses involving sequential crack propagation because of the built-in crack growth and remeshing capabilities of the program (Wawrzynek and Ingraffea, 1987).

For finite-element modeling of a MR test, the important aspects of the modeling procedure include the model boundary conditions, the fineness of the model mesh and the method of calculation for crack-tip stressintensity factors (Fischer and others, in press). The finiteelement mesh and boundary conditions we used are shown in Figure 4. Slip was allowed between the specimen and the loading platen, a modified crack-closure integral Rybicki and Kanninen, 1977; Bittencourt and others, 1992) algorithm was used to calculate the cracktip stress-intensity factors and the crack-tip mesh was refined to a point where the stress-intensity factors did not change with further refinement. Previous uses of the MR test on rock employed constant-force boundary conditions (Thiercelin, 1987; Thiercelin and Roegiers, 1987; Thiercelin and others, 1987) and yield solutions that are valid for a given Young's modulus $(E)$ and Poisson ratio $(\nu)$. However, as noted by Fischer (1994), application of constant force along the specimen-loading surface results in several complications, including an unrealistic nonuniform displacement distribution along the loading

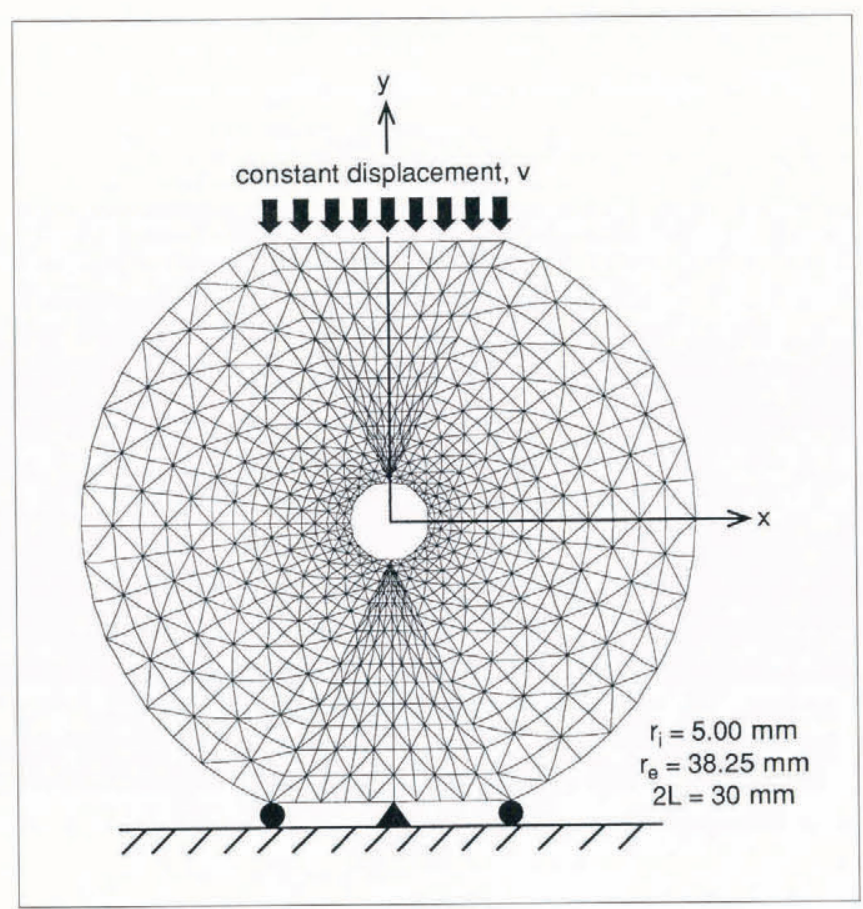

Fig. 4. Finite-element mesh and boundary conditions used in this study. Model is shortened from the top, fixed in the $y$ direction along the entire boltom-loading surface length, and fixed in $x$ and $y$ at the midpoint of the bottom-loading surface. Note that this specific mesh is used only for the synthetic ice specimens. A similar mesh with different dimensions is used for the fracture-loughness tests on the firn. surfaces and a significant influence of slip and no-slip boundary conditions on the $K_{\text {Imax }}$ determined from the finite-element model.

Because we feel that constant-displacement boundary conditions more appropriately simulate the action of the loading platen on the specimen, numerical modeling in our study is conducted by applying a uniform displacement to the specimen-loading surfaces. The technique we employ follows that of Fischer and others (in press) and yields results that are relatively insensitive to slip between the specimen and the loading platen, and that are independent of Young's modulus and the Poisson ratio of the specimen. In this approach, a series of finiteelement models is conducted wherein a crack is propagated in a model MR specimen with fixed material properties under different magnitudes of constant displacement or the model material properties are varied under a fixed displacement. In each of these models, axial stress $(\sigma)$ and mode I stress intensity $\left(K_{\mathrm{I}}\right)$ are calculated during sequential propagation of axial cracks from the central hole in the model specimen (Fig. 5). Fischer and others (in press) showed that, although the absolute magnitudes of $K_{\mathrm{I}}$ and axial stress $(\sigma)$ vary between each model after each increment of crack growth, the ratio of axial stress to $K_{\mathrm{I}}$ at any stage of crack growth is a constant, effectively independent of material elastic properties and displacement. This suggests that the ratio of axial stress at the critical crack length, $\sigma_{\mathrm{ac}}$, to maximum stress-intensity factor observed in the finiteelement model, $K_{\operatorname{Imax}}$, may be used to determine the fracture toughness of an identical test specimen using the relationship

$$
\left(\frac{\sigma_{\mathrm{ac}}}{K_{\mathrm{Imax}}}\right)_{\text {model }}=\left(\frac{\sigma_{\mathrm{ac}}}{K_{\mathrm{Ic}}}\right)_{\text {lab }} .
$$

The fracture toughness of a specimen subjected to constant displacement-boundary conditions is determined simply by dividing the stress measured in the laboratory at time $t_{\mathrm{c}}$ (Fig. 2) by the ratio of $\sigma_{\mathrm{ac}}$ to $K_{\operatorname{Imax}}$ determined from the finite-element model. The ratio $\sigma_{\text {ac }} / K_{\operatorname{Imax}}$ has units of (length) $)^{-\frac{1}{2}}$ and is essentially a shape factor characterizing the geometry of the particular MR specimen analyzed in the finite-element model. This shape factor is analogous to the term $\left(Y^{-1}(\pi c)^{-\frac{1}{2}}\right)$ from Equation (1) and can be used to calculate the fracture toughness of any linear elastic material with the same normalized dimensions as the model specimen (i.e. $r_{\mathrm{i}} / r_{\mathrm{e}}$, $2 L / r_{\mathrm{e}}$; Fig. 1).

\section{Sample preparation}

Two sets of modified ring experiments were conducted to determine the fracture toughness of granular fresh-water ice and firn. Facilities available allowed for only limited precision in all stages of sample preparation. Rightcircular cylinders of granular fresh-water ice Ih were manufactured in a several-step process. Deionized water was first frozen in ice-cube trays at temperatures between $-20^{\circ}$ and $-25^{\circ} \mathrm{C}$. These ice cubes were crushed into angular fragments ranging in size from 1 to $15 \mathrm{~mm}$. The crushed ice was poured into an $18 \mathrm{~cm}$ long section of $76.2 \mathrm{~mm}$ diameter PVC pipe with a rubber cap on one 

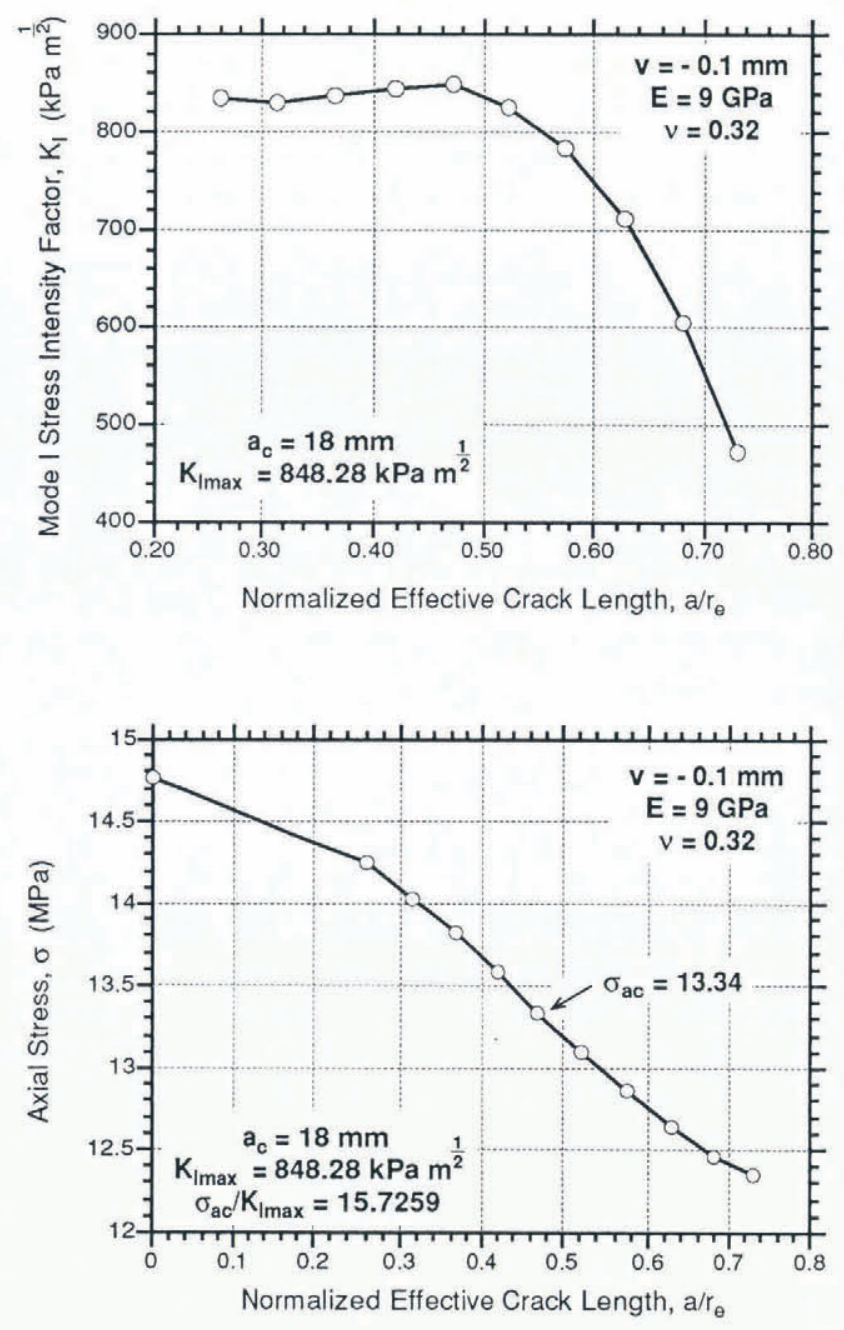

Fig. 5. Variation in $K_{\mathrm{I}}(a)$ and axial stress (b) which resulted during crack growth when a modified ring specimen with normalized dimensions of $r_{\mathrm{i}} / r_{\mathrm{e}}=0.1307$, $2 L=0.7843$, material properties of $E=9 \mathrm{GPa}$ and $\nu=$ 0.32 is compressed by $0.1 \mathrm{~mm}$. Crack is allowed to propagale in $2 \mathrm{~mm}$ increments starting at $a=10 \mathrm{~mm}$. Axial stress at $a=0$ shown for reference. Note that axial stress does not increase after $\sigma_{\mathrm{ac}}$ as shown in Figures 2 and 3 , because the model is subjected to a constant displacement and the increase in stress recorded in the laboratory is related to the continuously increasing displacement applied in the laboratory. Also note the difference in the horizontal scales between the two graphs.

end. The PVC pipe filled with crushed ice was then filled with supercooled, deionized water and allowed to freeze at $-10^{\circ}$ to $-15^{\circ} \mathrm{C}$ for a minimum of $12 \mathrm{~h}$. Water used in all stages of specimen preparation was not degassed, resulting in moderately bubbly, granular ice with an average density of $0.891 \mathrm{Mg} \mathrm{m}^{-3}$ and average porosity of $\sim 3 \%$.

An ice cylinder was removed from the PVC pipe by warming at temperatures from $15^{\circ}$ to $30^{\circ} \mathrm{C}$ until the specimen slid easily out of the PVC jacket. The duration of warming varied from 10 to $30 \mathrm{~min}$. Differential melting during this time often resulted in a cylinder that was up to $1 \mathrm{~mm}$ narrower at the ends than in the center. Insulation of both ends of the specimen during warming reduced this effect. The final diameter of the cylinders prior to machining was $76.5 \pm 0.5 \mathrm{~mm}$.

Figure 6 is a photograph of a thin section of typical granular, fresh-water ice produced for this study. The grains that resulted were frequently angular, not necessarily equidimensional, and range in size from 0.5 to $15 \mathrm{~mm}$. Grain-size varied in three dimensions within a given cylinder but the average grain-size calculated from six thin sections from four samples using the linear intercept method (Underwood, 1970) is $2.23 \mathrm{~mm}$ and is assumed to be representative of the entire group of samples. Grain $c$ axes within the specimens are assumed to have no preferred orientation. Because the ice that was manufactured does not physically resemble natural granular ice, which typically consists of equidimensional grains exhibiting a range of sizes in which the difference in maximum and minimum grain-size is less than the average grain-size (Alley, 1987b), we hereafter refer to our manufactured ice as synthetic ice.

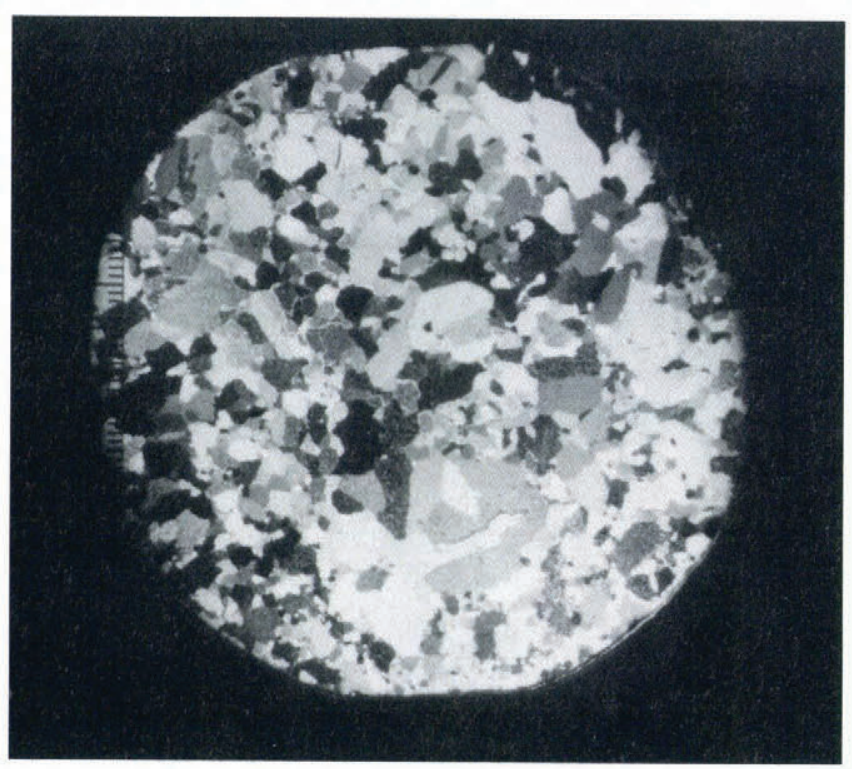

Fig. 6. Photograph of a thin section of granular, freshwater ice manufaclured for this study. Pholograph taken in polarized light. Smallest units on the scale at left of the photograph are millimeters.

Shallow core from the Greenland Ice Sheet Project II (GISP2) was used in MR tests to determine the fracture toughness of firn. The firn used in this study is from a $1.2 \mathrm{~m}$ long section of the GISP2 E core at depths from 26 to $27.2 \mathrm{~m}$. The core was stored at temperatures from $-20^{\circ}$ to $-25^{\circ} \mathrm{C}$, except during machining and deformation, which took place at temperatures from $-10^{\circ}$ to $-15^{\circ} \mathrm{C}$. The diameter of the core is $130.0 \pm 0.5 \mathrm{~mm}$ and, assuming the core is a right-circular cylinder with a radius of $65.0 \mathrm{~mm}$, the average density of the core is $0.605 \mathrm{Mg} \mathrm{m}^{-3}$ and the average porosity is $\sim 34 \%$. These values are in agreement with previously determined densities for GISP2 ice-core firn from similar depths (personal communication from R. B. Alley). The average grain-size of the firn was not rigorously determined but 
cursory visual examination suggests it is approximately $1 \mathrm{~mm}$ (Fig. 7). Grain $c$ axes are assumed to have no preferred orientation.

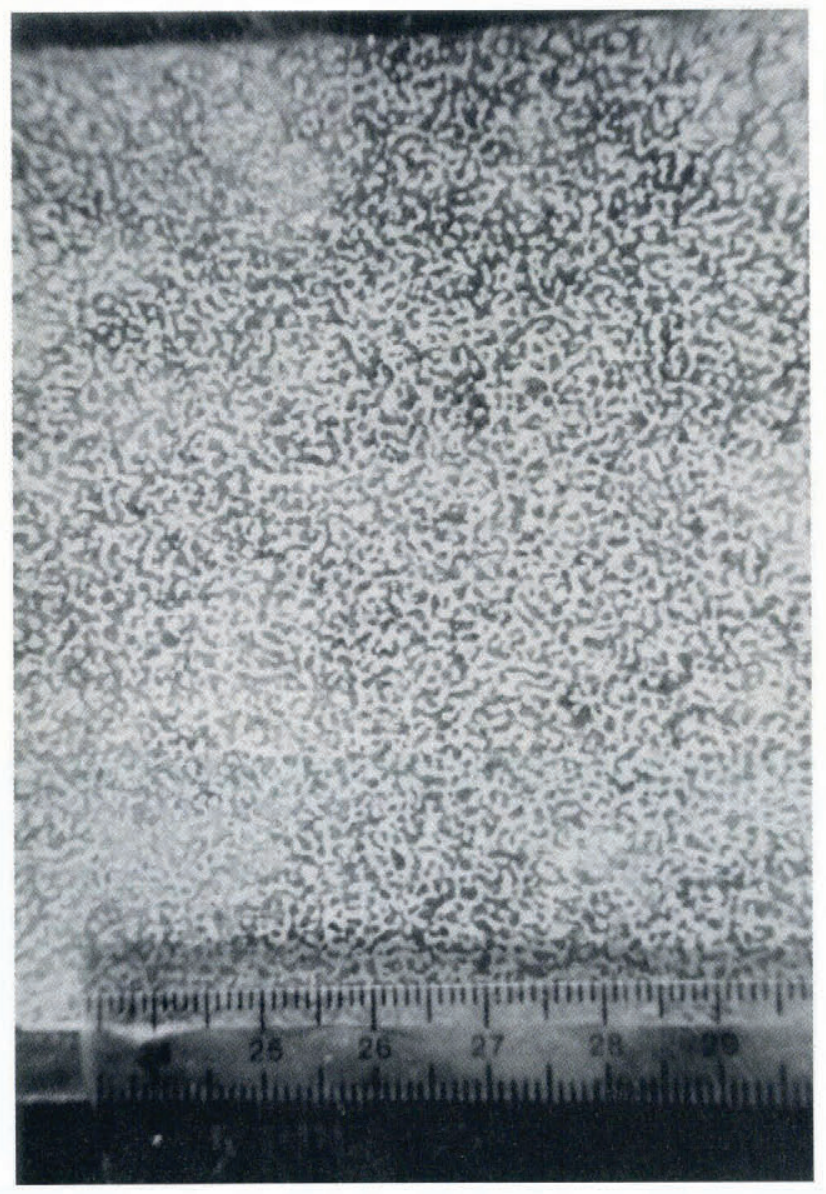

Fig. 7. Photograph of a thin section of some of the GISP2 firn used in this study. Photograph laken in plane light. Gray areas are $\mathrm{H}_{2} \mathrm{O}$ ice, whereas the white areas are frozen dimethyl phthalate with which the specimen was impregnated prior to sectioning. Smallest units on the scale are millimeters.
Figure 8 is a photograph showing the MR specimens used for synthetic ice and firn. All firn and synthetic ice specimens were cut to a thickness $(W$; Fig. la) of $30 \pm 0.5 \mathrm{~mm}$ and loading surfaces were machined to $\pm 0.5 \mathrm{~mm}$ of the desired length $(2 L$; Fig. la) using a bandsaw. The porous nature of the firn resulted in irregular edges to the loading surfaces of these specimens such that the width of the loading surface may vary by $\pm 1 \mathrm{~mm}$ locally. The loading surfaces of the synthetic ice specimens were smoothed by sanding on a fine $(\sim 0.5 \mathrm{~mm}$ square mesh) aluminum screen. We did not smooth the bandsaw cuts on the sides of any of the specimens nor did we attempt to smooth the loading surfaces of the firn specimens. The central holes in the specimens were machined with a hand-held power drill attached to a miniature drill press. Chipping at the perimeter of the hole was common but this was primarily a surficial effect which had no impact on the test results. In the more internal parts of the specimen, the surface of the hole was smooth and free of artificial defects. Centering of the hole proved difficult, with many holes displaced by $\pm 1 \mathrm{~mm}$ in the horizontal and/or vertical direction.

The synthetic ice and firn specimens were deformed in a $\sim 75 \mathrm{~cm}$ tall load frame designed and built at The Pennsylvania State University and located in a refrigerated laboratory (see Fischer (1994) for a detailed description of this apparatus). The load frame is constructed of mild steel and the loading platens are simple flat steel plates. We did not measure the compliance of the machine but note that the combined cross-sectional area of the tie rods connecting the ram to the loading platens is roughly twice the loading surface area of either of the two sample geometries used in this study. We made no attempt to lubricate the specimen-platen interface because, as noted by Fischer (1994) and Fischer and others (in press), results from numerical models of the modified ring test are essentially independent of the slip conditions at the specimen-platen interface.

The time-varying voltage from a hollow BeCu load cell and a linear variational displacement transducer were

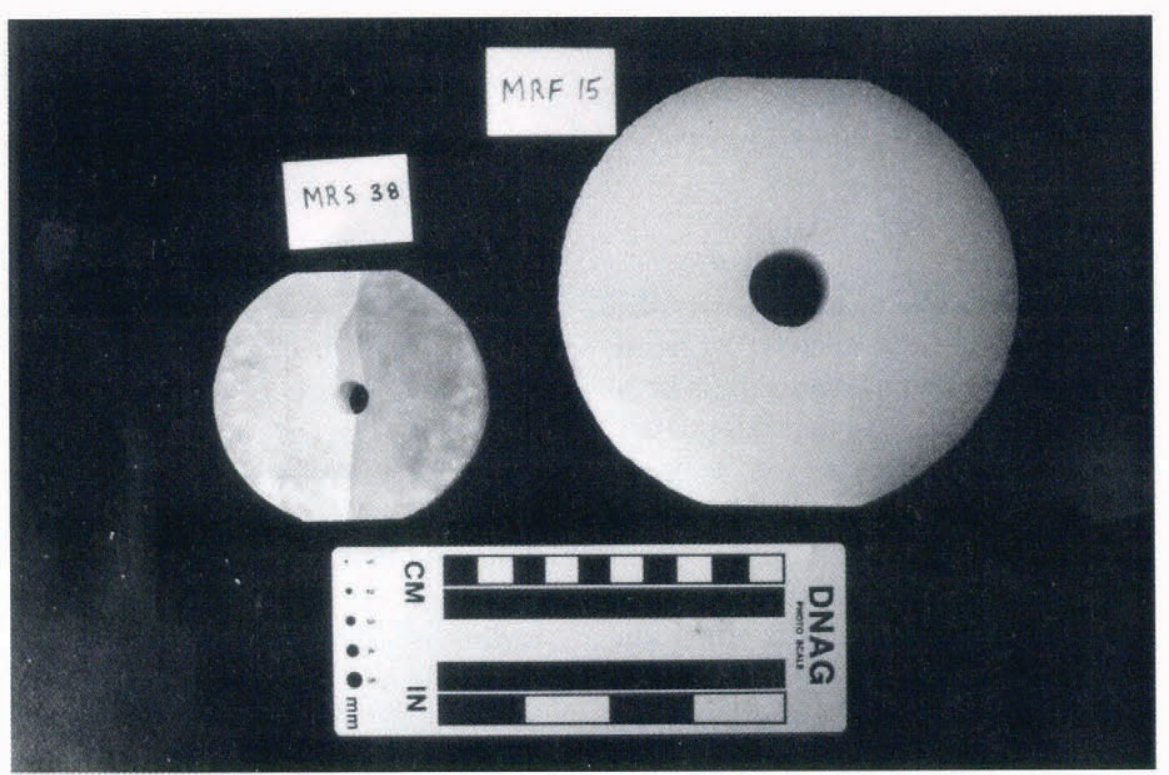

Fig. 8. Two types of modified ring specimens used in this study. Smaller MRS specimen is of synthetic, granular, fresh-water ice, whereas the larger MRF specimen is of firn from the GISP2 E core. 
continuously monitored during each experiment in order to maintain a record of the axial load on the specimen and the displacement of the ram head. Because the hydraulic power supply controlling the displacement of the ram head is manually operated, it was not possible to conduct all experiments at exactly equal displacement or loading rates. We nevertheless attempted to maintain similar displacement rates in all experiments and, as shown in Figure 9, the average displacement rate for all the tests was near $0.5 \mathrm{~mm} \mathrm{~min}^{-1}$.
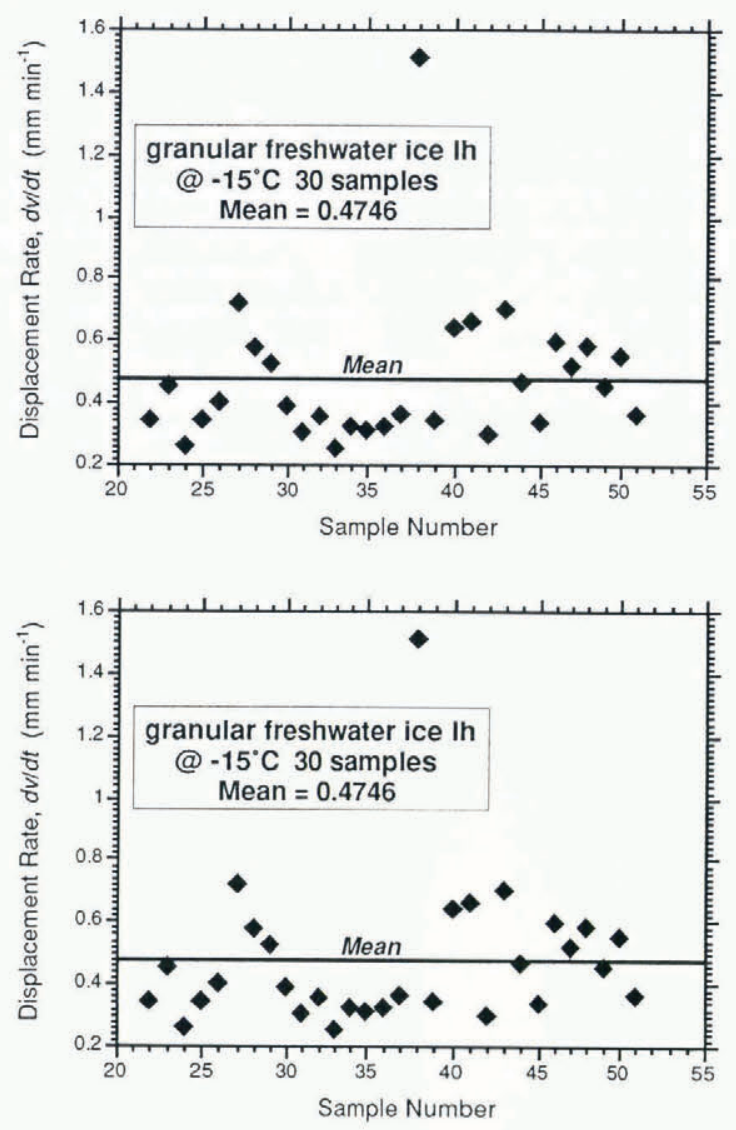

Fig. 9. Rate of displacement of the ram head during each of the modified ring tests done on synthetic fresh-water ice and firn.

\section{RESULTS}

Modified ring tests were conducted on 30 specimens of synthetic ice. Normalized dimensions of the specimens are $r_{\mathrm{i}} / r_{\mathrm{e}}=0.1307$ and $2 L / r_{\mathrm{e}}=0.7843$. The ratio of $\sigma_{\mathrm{ac}} /$ $K_{\text {Imax }}$ determined for the size of specimen is $15.7880^{*}$

\footnotetext{
"This value and that reported for the firn specimens represent the average of results obtained for seven Poisson ratios $(\nu)$ from 0.1 through 0.4 , assuming frictionless slip at the specimen platen interface. Fischer and others (in press) demonstrated that, for this range of $\nu$, variation in $\sigma_{\mathrm{ac}} / K_{\operatorname{Imax}}$ due to inaccurate constraint on $\nu$ is less than $0.6 \%$ If slip is not allowed at the specimen-platen interface, the results for $\sigma_{\mathrm{ac}} / K_{\operatorname{Imax}}$ differ by less than $2.0 \%$.
}

(Fischer and others, in press). Because of machining errors which resulted in asymmetric crack propagation, viable results were obtained from $66 \%$ of the specimens. The average $K_{\text {Ic }}$ determined from these 20 specimens is $145.7 \mathrm{kPa} \mathrm{m}^{\frac{1}{2}}$, with a standard deviation of $24.0 \mathrm{kPa} \mathrm{m}^{\frac{1}{2}}$ (Fig. 10). The relatively large standard deviation of the results should be significantly reduced with more accurate machining; in particular, the accuracy of positioning of the central hole of the specimen proved critical in obtaining valid, reproducible tests with these smaller samples.

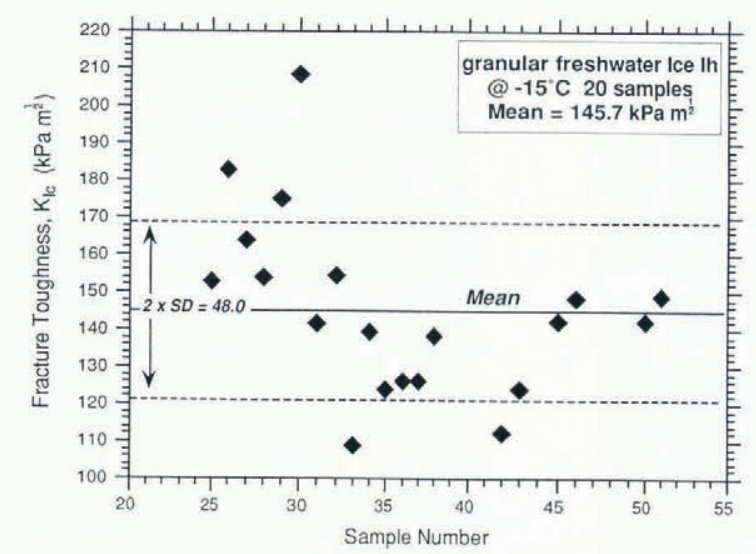

Fig. 10. Fracture-toughness values for each of the modified ring tests done on synthetic, granular, fresh-water ice.

For specimens with holes displaced from the center by 0.5-1.0 mm, crack propagation was not always symmetric in that often only one axial crack formed or the cracks did not initiate from the apices of the hole. For cases where the cracks did not initiate from the hole apices, the cracks initiated from the hole perimeter but were displaced 2 or $4 \mathrm{~mm}$ clockwise or counter-clockwise from the hole apices. We attribute this behavior partly to machining errors and partly to the inhomogeneity of the synthetic ice samples due to the rather large variation in grain-sizes. Although these were common modes of failure in our experiments, we could not eliminate this behavior because of the limited precision of our machining and sample-preparation facilities. Inclusion of results obtained from these specimens in our final data set certainly increased the standard deviation of the data. In specimens with holes displaced from the center by greater than $1.5 \mathrm{~mm}$, failure did not occur by crack propagation from the hole. Instead, the specimen failed by growth of one or two cracks that extended across the specimen between the loading surfaces, gently curving around the central hole in the specimen. Specimens failing by this mechanism were considered invalid and were not included in the final data set.

We are not aware of fracture-toughness values for firn in the current literature. We conducted our tests on specimens with normalized dimensions of: $r_{\mathrm{i}} / r_{\mathrm{e}}=0.1709$ and $2 L / r_{\mathrm{e}}=0.6154$. The ratio of $\sigma_{\mathrm{ac}} / K_{\operatorname{Imax}}$ determined for specimens with these normalized dimensions is 9.7003 . Modified ring tests conducted on 20 specimens of firn from a depth of $26-27.2 \mathrm{~m}$ in the GISP2 $\mathrm{E}$ core yielded an 
average fracture toughness of $108.6 \mathrm{kPam}^{\frac{1}{2}}$, with a standard deviation of $8.6 \mathrm{kPa} \mathrm{m}^{\frac{1}{2}}$ (Fig. 11). These results were obtained from a finite-element model assuming constant displacement and slip-allowed boundary conditions (see footnote). Machining accuracy did not play a significant role in determining fracture toughness of the firn because of the larger size of these specimens and because of the uniformly small grain-size of the firn. With larger specimens, uniformly small grain-sizes and larger holes, even errors of $\pm 2 \mathrm{~mm}$ in centering of the hole did not cause the crack to initiate at the specimen loading surfaces. Larger specimen sizes should be used whenever possible.

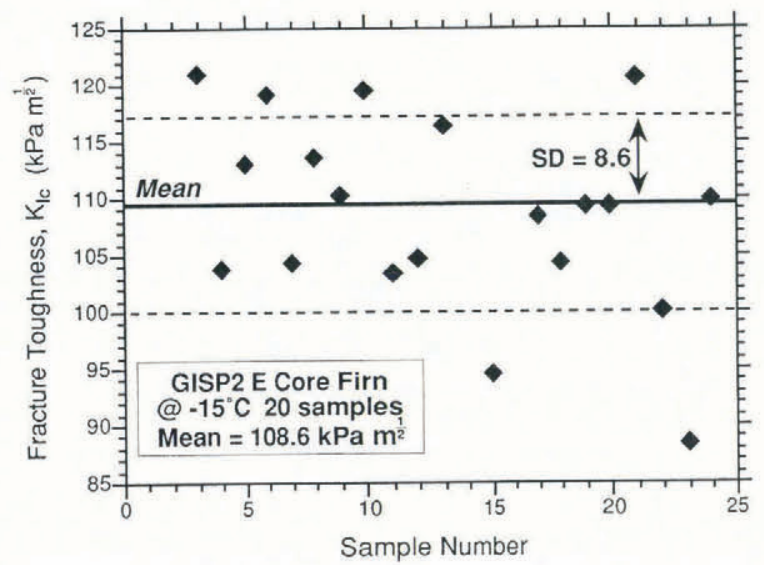

Fig. 11. Fracture-toughness values for each of the modified ring tests done on firn from the GISP2 E core.

The behavior of the firn samples was much more consistent than that of the synthetic ice. All specimens failed by the formation of two axial cracks that initiated from the apices of the specimen hole. Like the synthetic ice, firn specimens remained intact after unloading. Cracks in the firn were not visible without the precise combination of back and front lighting, oriented at just the right angle to the sample. In this lighting, the cracks were visible as straight, planar, darkened lines that appeared to consist of granulated ice.

\section{Porosity effects}

Smith and others (1990) investigated the effects of porosity on the fracture toughness of granular freshwater ice. In their study, porosity was introduced to the ice by either not degassing the water prior to freezing or by freezing carbonated water. The fracture toughness of samples tested by Smith and others (1990) decreased by $25 \%$ over a range of porosities $(\phi)$ from 0 to $15 \%$. Smith and others (1990) attempted to explain these results in the context of a porosity-dependent Young's modulus which is well-defined for porous ceramics (e.g. Krstic and Erickson, 1987). And, after deriving a relation between $E(\phi=0)$ and $E(\phi \neq 0)$, Smith and others (1990) used the relation between fracture toughness $\left(K_{\mathrm{Ic}}\right)$ and critical fracture energy $\left(G_{\text {Ic }}\right)$ (see Broek, 1986) to derive two possible expressions for the porosity-dependent fracture toughness of ice:

$$
\begin{aligned}
& K_{\mathrm{Ic}}(\phi)=K_{\mathrm{Ic}}(\phi=0)\left[\frac{(1-\phi)^{2}}{(1+7 \phi)}\right]^{\frac{1}{2}}, \\
& K_{\mathrm{Ic}}(\phi)=K_{\mathrm{Ic}}(\phi=0)\left[\frac{(1-\phi)}{(1+7 \phi)}\right]^{\frac{1}{2}} .
\end{aligned}
$$

According to Smith and others (1990), Equation (3) incorporates the effect of porosity on $G_{\text {Ic }}$ whereas Equation (4) neglects it.

Figure 12 shows the porosity fracture-toughness relations of Equations (3) and (4) along with the average fracture-toughness values determined for the two porosities examined in this study. The quality of the fit between the data and the theoretical relations is significantly affected by the chosen value of $K_{\mathrm{Ic}}(\phi=0)$. The best fit between the two data points and the theoretical curves occurs when $K_{\mathrm{Ic}}(\phi=0)$ is roughly $200 \mathrm{kPa} \mathrm{m}^{\frac{1}{2}}$. Although the data do not lie perfectly on the theoretical curves, they clearly support the conclusions of Smith and others (1990) by demonstrating a reduction in $K_{\text {Ic }}$ with ice porosity. We have requested further samples to allow us to define this relation with natural ice and firn at a variety of densities.

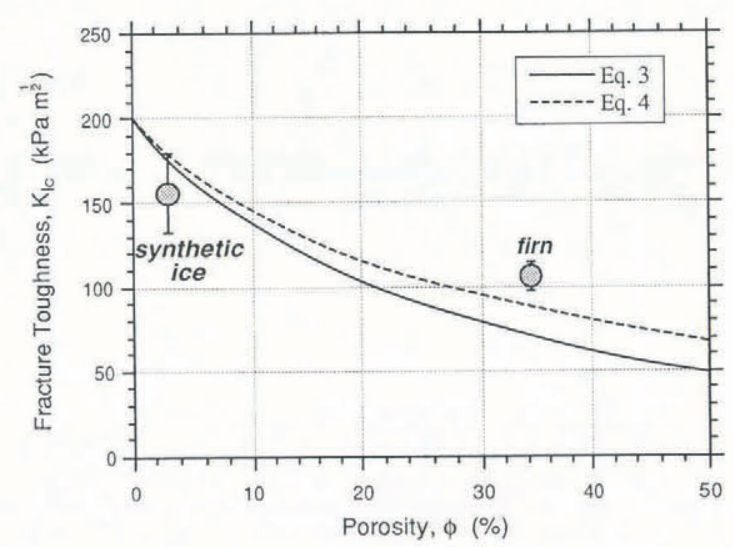

Fig. 12. Correlation between the decrease in fracture toughness with increasing porosity observed in this study with the theoretical curves derived by Smith and others (1990).

The influence of porosity on ice fracture toughness is an important relationship, especially when dealing with near-surface or vertical fractures in ice sheets and glaciers. Because firn density increases with depth, fracture toughness should likewise increase, a result likely to affect the penetration depth and initiation of crevasses. Moreover, lateral variations in firn density may impact on the horizontal distribution of crevasse fields or the trace length of individual crevasses. The future integration of firn-densification models (e.g. Herron and Langway, 1980; Alley, 1987a) with a model of porositydependent fracture toughness should further our understanding of the three-dimensional variation of ice-fracture resistance in ice sheets and glaciers. 


\section{ADVANTAGES OF THE MODIFIED RING TEST}

Prior to this work, nearly all existing data constraining the fracture toughness of ice were generated using test specimens in which $K_{\text {Ic }}$ is related to the load required to initiate a crack from a notch machined in a test specimen. A variety of test specimens has been used, including compact tension (Liu and Miller, 1979), tensile- Parsons and others, 1986; Bentley and others, 1988) and wedgeloaded rectangular, double cantilever beams (Liu and Miller, 1979), three- (Andrews and others, 1984; Timco and Frederking, 1986; Wei and others, 1990) and fourpoint bending (Dempsey and others, 1989a; Weber and Nixon, 1992) of single-edge-notched beams, and circumferentially notched cylinders (Nixon and Schulson, 1986, 1987; Smith and others, 1990). In all of these specimens, the mode I stress-intensity factor at the tip of the starter notch increases with increasing load until the stress intensity reaches the fracture toughness of the ice, at which point a crack propagates from the notch. The plane-strain fracture toughness of the ice is proportional to the load at crack initiation.

Existing work on the fracture toughness of ice suggests $K_{\text {Ic }}$ of ice is dependent on a variety of extrinsic and intrinsic factors including temperature (Nixon and Schulson, 1987), average grain-size (Nixon and Schulson, 1986), loading rate (Nixon and Schulson, 1987), ice fabric (Parsons and others, 1986; Weber and Nixon, 1992), volume fraction of included particulate matter (Smith and others, 1990), notch acuity (Wei and others, 1990; DeFranco and others, 1991), specimen size and crack length (Dempsey and others, 1989a,b). Because of these effects, Dempsey and others (1989a) proposed ice fracture-toughness data should be reported as "apparent fracture toughness", $K_{\mathrm{Q}}$, accompanied by a detailed description of the testing conditions. We submit that many of these effects are products of a testing method in which fracture toughness is related to the load necessary to initiate a crack from a specimen starter notch. Use of such specimens has clouded the distinction between testing effects and true material behavior. As discussed below, we believe the unique geometry of the MR test effectively eliminates some of these effects and may also eliminate others, facilitating faster, easier testing with results showing significantly less scatter.

\section{Loading rate}

For situations in which fracture toughness is related to the tensile load required to initiate a crack at the tip of a starter notch, loading rate is typically reported as the time rate of change of the mode I stress-intensity factor at the tip of the notch (i.e. $\mathrm{d} K_{\mathrm{I}} / \mathrm{d} t$ or $\dot{K}_{\mathrm{I}}$; e.g. Miller, 1984; Nixon and Schulson, 1987; Dempsey and others, 1989a, b). Previous work on the fracture toughness of ice suggests $K_{\text {Ic }}$ increases with decreasing loading rate (e.g. Liu and Miller, 1979; Nixon and Schulson, 1987). This result is expected in a creeping material such as ice, because at low loading rates the tensile-stress concentration at the tip of the specimen starter notch may be partially relieved by localized, nonrecoverable creep, thus increasing the energy required to initiate a crack, resulting in higher apparent fracturetoughness values. Nixon and Schulson (1987) suggested that above some threshold loading rate, $\dot{K}_{I}^{t}$, fracture toughness is independent of the rate of loading.

Use of a modified ring-specimen geometry should eliminate most rate effects on the fracture toughness of ice, because the fracture toughness in the MR test is measured at the tip of a natural crack at the instant it passes from unstable to stable propagation. Consequently, there is no time for creep deformation to relax the crack-tip stress field. Although this remains to be evaluated in detail, data over the limited range of displacement rates in this study suggest this is the case (Fig. 13). Rate effects observed with the MR test should only be related to the initiation load of the crack $\left(\sigma_{i}\right.$; Fig. $\left.2 \mathrm{a}\right)$ because creep deformation will most likely be concentrated around the periphery of the specimen hole and thereby influence the load at which a crack will initiate. However, because $K_{\text {Ic }}$ is not measured until a crack has propagated out of that part of the specimen influenced by the presence of the hole (Thiercelin and Roegiers, 1987) and any associated creep deformation, the minimum in the load versus time curve for a MR test, and hence, $K_{\text {Ic }}$, should be free of rate effects.

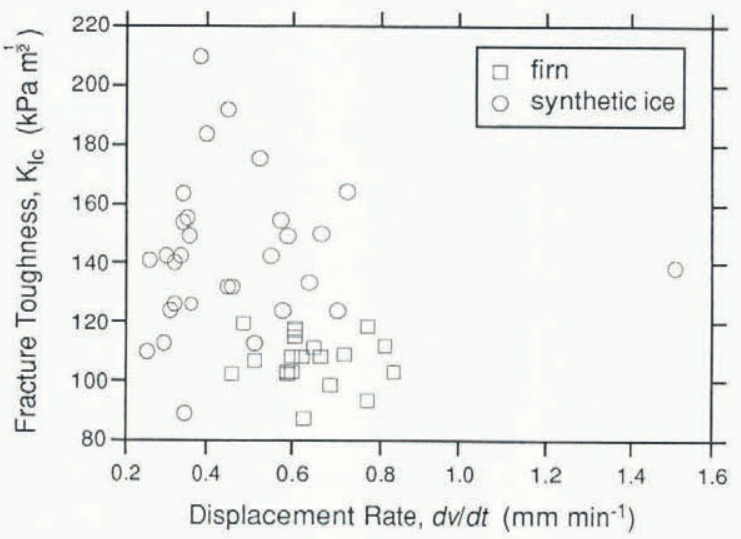

Fig. 13. Relationship between ram-head displacement rate and fracture toughness recorded during fracture-toughness tests on synthetic, granular, fresh-water ice and GISP2 E core firn.

\section{Notch acuity}

One of the basic tenets required for the valid application of linear elastic fracture mechanics is that cracks have sharp tips (i.e. radius of curvature $=0$; Broek, 1986). In rock, ceramic and concrete test specimens this does not present a significant problem because low-amplitude cyclic loading of a notched specimen produces sharp fatigue cracks at the notch tip. Although recent work by Nixon and Weber (1991) has demonstrated that ice is susceptible to fatigue cracking, this technique has not been used to create starter cracks in fracture-toughness tests of ice. Consequently, ice researchers typically machine sharp cracks at the tips of the starter notches of their test specimens. Variation in the techniques used to produce such sharp cracks has resulted in a variation in fracture toughness with notch acuity (sharpness).

Wei and others (1990) and DeFranco and others (1991) characterized the effect of notch acuity on the fracture toughness of ice. Their results indicate that the 
fracture toughness of ice is greater for specimens with blunt starter notches. This occurs because the stress intensity at the tip of a starter notch is proportional to the sharpness of the notch. Specimens with blunt notches will fail at higher tensile loads, thereby yielding higher $K_{\mathrm{Ic}}$ values, because the tensile stress at the tip of a blunt notch is less than that developed at the tip of a sharp notch subjected to the same tensile load. To eliminate the effects of notch acuity on the fracture-toughness testing of ice, a standardized technique for machining sharp notches involving scribing the tip of a bandsaw-cut notch with a razor blade was proposed by Wei and others (1990) and DeFranco and others (1991).

The effects of notch acuity on the fracture toughness of ice are effectively eliminated in the modified ring test because the fracture toughness is not measured when a crack initiates from a machined starter notch. Instead, $K_{\text {Ic }}$ is measured at the tip of a natural crack after it has propagated some distance away from the edge of the central hole in the specimen. Measuring $K_{\text {Ic }}$ at the tip of a propagating natural crack insures a sufficiently sharp crack tip in every experiment.

\section{Grain-size, specimen size and crack length}

Nixon and Schulson $(1986,1987)$ reported that the fracture toughness of ice increased with decreasing grainsize. However, this result was questioned by Dempsey and others $(1989 \mathrm{a}, \mathrm{b})$, who measured the fracture toughness of ice using single-edged-notched beam (SENB) and rectangular, double-cantilever beam specimen geometries, and suggested the apparent grain-size dependence of fracture toughness reported by earlier workers may have resulted from the use of sub-sized specimens. Dempsey and others (1989a,b) further stated that nearly all previous fracture-toughness data were invalid because they were derived from similarly sub-sized specimens and presented guidelines for standardizing specimen preparation and testing. Within these guidelines are minimum ratios of specimen depth to average grain-size and crack length to average grain-size required for valid LEFM testing. The minimum ratios are suggested because they represent a theshold ratio above which apparent fracture toughness, $K_{\mathrm{Q}}$, appears to be independent of the specimen depth and crack length.

In rocks, ceramics, concrete and metals, specimen-size requirements are designed to insure either plane-strain testing conditions, a critical amount of stable-crack extension prior to unstable-crack growth (Matsuki, 1991) or a minimum extent of inelastic crack-tip deformation (e.g. Schmidt, 1980). Plane strain is required in the testing of materials with a fixed yield stress (e.g. metals) because the size of the crack-tip plastic zone in these materials increases dramatically under plane-stress conditions, resulting in greater fracture energies. Critical crack-extension and crack-length requirements are based on the hypothesis that unstable crack growth in concrete and rocks can only occur after the formation of an equilibrium-sized brittle process zone Hu and Wittmann, 1990; Jankowski and Stys, 1990; Swartz and Shah, 1991). Formation of this process zone is believed to occur during stable growth of the crack over some critical length.
The physical basis for the dependence of ice fracture toughness on specimen size and crack length is unclear. Differences in ice behavior due to the entirely different stress state (i.e. plane strain or plane stress) that might be present in smaller samples are possible but have not been documented. A criterion for minimum crack length in ice specimens states that crack lengths should be at least 50 times the size of the region of inelastic deformation surrounding the crack tip (Dempsey and others, 1989a). Although this is described as a size requirement, this stipulation is actually a loading-rate effect associated with the creep of ice at the crack tip. As discussed by Riedel and Rice (1980), the extent of inclastic deformation surrounding a crack tip in a creeping solid is linearly proportional to the duration of loading. This relationship led Timco and Frederking (1986) to suggest a maximum allowable time between the crack sharpening and failure stages of an ice fracture-toughness test. As discussed above, fracture-toughness values determined with the MR test should be free of creep-related rate effects and therefore crack-length requirements based on estimation of creep-zone size are not necessary for the MR test.

Size effects on the apparent fracture toughness of ice may primarily reflect the differences in the fracture behavior of multi-crystalline and polycrystalline ice (Nixon and Schulson, 1986). So-called sub-sized specimens may simply not be representative of polycrystalline material behavior. Nixon and Schulson (1986) stated that there is no quantitative measure of the number of grains necessary to constitute polycrystalline behavior in ice, but suggested that the smallest specimen dimension should equal at least ten grain diameters. With an average grainsize of $\sim 1 \mathrm{~mm}$, all of the firn specimens tested in this study easily meet this requirement. However, because of the variability of grain-sizes between specimens of the synthetic granular ice, it is possible that some of these specimens do not exhibit polycrystalline behavior. This may further account for the relatively large standard deviation for the synthetic ice fracture-toughness values presented in this study. Further testing with finer-grained natural ice samples is required to elucidate this problem fully.

\section{GONCLUSIONS}

Modified ring tests conducted on synthetic, granular fresh-water ice and firn from the GISP2 E core respectively yield average fracture-toughness values of 145.7 and $108.6 \mathrm{kPam}^{\frac{1}{2}}$. Our results show a decrease in fracture toughness with increasing ice porosity and confirm the general conclusions of Smith and others (1990). Continued study of firn fracture toughness will provide further insight into porosity effects on ice fracture toughness and advance our understanding of the threedimensional variation in fracture resistance of glaciers and ice sheets. We believe use of a modified ring-specimen geometry should eliminate many of the factors currently complicating the fracture-toughness testing of ice. Loading rate, notch acuity, crack-length and specimen-size requirements for notched-specimen geometries are not necessary for the modified ring test. Elimination of these testing complications should allow for an unclouded view of other parameters influencing ice-fracture toughness. 


\section{ACKNOWLEDGEMENTS}

This paper represents a part of M. P. Fischer's Ph.D. dissertation at The Pennsylvania State University. We should like to thank A. R. Ingraffea for providing the finite-element program FRANC. T. Bittencourt, D. Swenson and P. Wawrzynek provided excellent technical support during our use of the program. D. Elsworth and S. Anandakrishnan provided valuable comments and advice during this project. Formal review of this manuscript by S.J. DeFranco is gratefully acknowledged. The firn for this study was obtained with the assistance of the Polar Ice Coring Office, the GISP2 Science Management Office and the 109th New York Air National Guard. Funding for this project was provided by the David and Lucile Packard Foundation and U.S. National Science Foundation grants DPP-8822027 and DPP-8915995 to R.B. Alley.

\section{REFERENCES}

Alley, R. B. 1987a. Firn densification by grain-boundary sliding: a first model. J. Phys. (Paris), 48, Colloq. C1, 249 -256. (Supplément au 3.

Alley, R. B. 1987b. Texture of polar firn for remote sensing. Ann. Glaciol., 9. $1-4$.

Andrews, R.M., A.R. McGregor and K.J. Miller. 1984. Fracture toughness of glacier ice. In Miller, K.J., ed. The International Karakoram Projed. Vol. 1. Cambridge, etc., Cambridge University Press, 147-159.

Barsoum, R.S. 1976. On the use of isoparametric finite elements in linear fracture mechanics. Int. J. Numer. Methods Eng., 10, 25-37.

Bentley, D. L., J. P. Dempsey, D. S. Sodhi and Y. Wei. 1988. Fracture of S2 columnar freshwater ice: floating double cantilever beam tests. In Sacki, H. and K.-i. Hirayama, eds. Proceedings, the 9th International Symposium on Ice, 23-27 August 1988, Sapporo, Japan. Vol. 1. Delft, International Association for Hydraulic Research. Committce on Ice Problems, 152161.

Bittencourt, T. N., A. Barry and A. R. Ingraffea. 1992. Comparison of mixed-mode stress intensity factors obtained through displacement correlation, J-integral formulation, and modified crack-closure integral. In Atluri, S. N., J. C. Newman, Jr, I.S. Raju and J.S. Epstein, eds. Fracture mechanics. Proceedings of the 22nd National Symposium on Fracture Mechanics. Philadelphia, PA, American Society of Testing and Materials, 69-82. Special Technical Publication 2.

Broek, D. 1986. Elementary engineering fracture mechanics. Alphen aan den Rijn, Sijthoff and Noordhoff International Publishers.

Danilenko, V.I. 1985. Determination of crack resistance $\left(K_{\mathrm{IC}}\right)$ of freshwater ice. Mech. Solids, 20, 131-136.

DeFranco, S.J., Y. Wei and J. P. Dempsey, 1991. Notch-acuity effects on the fracture toughness of saline ice. Ann. Glaciol., 15, 23023.

Dempsey, J. P., Y. Wei, S. DeFranco, R. Ruben and R. Frachetti. 1989a. Fracture toughness of S2 columnar freshwater ice: crack length and specimen size effects. Part I. In Sinha, N. K., D.S. Sodhi and J.S. Chung, eds. Proceedings of the Eighth International Conference on Offshore Mechanics and Arctic Engineering. The Hague. The Nelherlands, March 19 23, 1989. Vol. 4. Arctic and polar lechnology. New York, American Society of Mechanical Engineers, 83- 89.

Dempsey, J.P., Y. Wei, S. DeFranco, R. Ruben and R. Frachetti. 1989b. Fracture toughness of S2 columnar freshwater ice: crack length and specimen size effects. Part II. In Axelsson, K. B. E. and L. A. Fransson, eds. POAC 89. The T0th International Conference on Port and Ocean Engineering under Arctic Conditions, June 12-16, Lulea, Sweden. Proceedings. Vol. 1. Luleå, Tekniska Högskolan i Luleå, 199 207.

Fischer, M.P. 1994. Application of linear elastic fracture mechanics to some problems of fracture propagation in rock and ice. Ph.D. thesis, Pennsylvania State University.

Fischer, M. P., D. Elsworth and R.B. Alley. In press. Finite element analysis of the modified ring test for determining mode I fracture toughness. Int. 7. Rock Mech. Min. Sci. Geomech. Abstr.

Goodman, D.J. and D. Tabor. 1978. Fracture toughness of ice: a preliminary account of some new experiments. J. Glaciol., 21 (85). $651-660$.

Herron, M. M. and C. C. Langway, Jr. 1980. Firn densification: an empirical model. j. Glaciol., 25 93), 373-385.
Hu, X. and F.H. Wittmann. 1990. Experimental method to determine extension of fracture-process zone. J. Mat. Civ. Eng., 2, 15-23.

Ingraffea, A. R. 1987. Theory of crack initiation and propagation in rock. In Atkinson, B. K., ed. Fracture mechanics of rock. London, Academic Press, 71-110.

Janowski, L.J. and D.J. Stys. 1990. Formation of the fracture process zone in concrete. Eng. Fract. Mech., 36, 245253.

Krstic, V.D. and W.H. Erickson. 1987. A model for the porosity dependence of Young's modulus in brittle solids based on crack opening displacement. J. Mater. Sci., 22, 2881-2886.

Lawn, R. 1993. Fracture of brillle solids. Second edition. Cambridge, Cambridge University Press.

Liu, H. W. and K.J. Miller. 1979. Fracture toughness of fresh-water ice. f. Glaciol., 22 (86), $135-143$.

Matsuki, K., S.S. Hasibuan and H. Takahashi. 1991. Specimen size requirements for determining the inherent fracture toughness of rocks according to the ISR.M suggested methods. Int. 7. Rock Mech. Min. Sci. Geomech. Abstr., 28, 365-374.

Miller, K.J. 1984. The mechanics of fracture applied to ice. In Miller, K.J., ed. The International Karakoram Project. Vol. 1. Cambridge, etc., Cambridge University Press, 135-146.

Nixon, W.A. and E. M. Schulson. 1986. The fracture toughness of ice over a range of grain sizes. In Lunardini, V.J., Y. S. Wang, O. A. Ayorinde and D.S. Sodhi, eds. Proceedings of the Fifth International Mechanics and Arctic Engineering (OM.AE) Symposium ... Tokyo, Japan, April 13 18, 1986... Vol. 4. New York, American Society of Mechanical Engineers, 349-353.

Nixon, W. A. and E. M. Schulson. 1987. A micromechanical view of the fracture toughness of ice. 7. Phys. (Paris), 48, Colloq. C1, 313-319. (Supplément au 3.

Nixon, W. A. and L.J. Weber. 1991. Fatigue-crack growth in freshwater ice: preliminary results. Ann. Glaciol., 15, 236241.

Parsons, B. L., J. B. Snellen and B. Hill. 1986. Physical modeling and the fracture toughness of sea ice. In Lunardini, V.J., Y.S. Wang, O. A. Ayorinde and D.S. Sodhi, eds. Proceedings of the Fifth International Mechanics and Arclic Engineering (O.MAE) Symposium ... Tokyo, Japan, April 13-18, 1986... Vol. 4. New York, American Society of Mechanical Engineers, 358-364.

Riedel, H. and J.R. Rice. 1980. Tensile cracks in creeping solids. In Fracture mechamics. Proceedings of the Twelfih National Symposium on Fracture Mechanics. Philadelphia, PA, American Society for Testing and Materials, 112-130. (Special Technical Publication 700.)

Rybicki, E. F. and M.F. Kanninen. 1977. A finite element calculation of stress intensity factors by a modified crack closure integral. Eng. Fracl. Mech., 9, 931-938.

Schmidt, R.A. 1980. A microcrack model and its significance to hydraulic fracturing and fracture toughness testing. In Summers, D. A., comp. Rock mechanics. Proceedings of the 21 st U.S. Symposium on Rock Mechanics. Rotterdam, A. A. Balkema, 581-590.

Smith, T. R., M.E. Schulson and E. M. Schulson. 1990. The fracture toughness of porous ice with and without particles. In Ayorinde, O.A., N. K. Sinha and D.S. Sodhi, eds. Proceedings of the Ninth International Conference on Offshore Mechanics and Arctic Engineering ... presented at ... Houston, Texas, February 18 23, 1990. Vol. 4. Arctic/polar lectmology. New York, American Society of Mechanical Engineers, 241-246.

Swartz, S. E. and S. P. Shah. 1991. Novel experimental techniques for damage evaluation in the fracture process zone in concrete and rock. Experimental Techniques, 15 3), 13.

Thicrcelin, M. 1987. Fracture toughness under confining pressure using the modified ring test. In Farmer, I. W., J.J. K. Daemen, C. S. Desai, C. E. Glass and S. P. Neuman, eds. Rock mechanics. Proceedings of the 28 th U.S. Symposium on Rock Mechanics. Rotterdam, A. A. Balkema, 149 156.

Thiercelin, M. 1989. Fracture toughness and hydraulic fracturing, Inl. J. Rock Mech. Min. Sci. Geomech. Abstr., 26, 177-183.

Thiercelin, M. and J. - C. Roegiers, 1987. Toughness determination with the modified ring test. In Hartman, H. L., ed. Rock mechanics: key to energy production. Proceedings of the 27th U.S. Symposium on Rock Mechamics. Littleton, CO, Society of Mining Engineers, 616-622.

Thiercelin, M., T.J. Boone, J. -C. Roegiers and A. R. Ingraffea. 1987. An investigation of the material parameters that govern the behavior of fractures approaching rock interfaces. In Herget, G. and S. Vongpaisal, eds. Proceedings of the Sixth International Congress on Rock Mechanics. Rotterdam, A. A. Balkema 263-269.

Timco, G. W. and R. M. W. Frederking. 1986. The effects of anisotropy and microcracks on the fracture toughness $\left(K_{\mathrm{Ic}}\right)$ of freshwater ice. In Lunardini, V.J., Y.S. Wang, O. A. Ayorinde and D. S. Sodhi, eds. Proceedings of the Fifth International Mechanics and Arctic Engineering 
(OMAE) Symposium ... Tokyo, Japan, April 13-18, 1986... Vol. 4. New York, American Society of Mechanical Engineers, 341-348.

Underwood, E. E. 1970. Quantitative stereology. Reading, MA, AddisonWesley Publishing Company.

Wawrzynek, P.A. and A. R. Ingraffea. 1987. Interactive finite element analysis of fracture processes: an integrated approach. Theor. Appl. Fract. Mech., 8, 137-150.

Weber, L.J. and W.A. Nixon. 1992. Fracture toughness of granular freshwater ice. In Ayorinde, O. A., N. K. Sinha, D. S. Sodhi and W.A. Nixon, eds. Proceedings of the 11th International Conference on
Offshore Mechanics and Arctic Engineering ... presented at ... Calgary, Alberta, Canada, June 7-12, 1992. Vol. 4. Arctic/polar technology. New York, American Society of Mechanical Engineers, 377-381.

Wei, Y., S. J. DeFranco and J. P. Dempsey, 1990. Notch acuity effects on the fracture toughness of freshwater ice. In Ayorinde, O.A., N.K. Sinha and D.S. Sodhi, eds. Proceedings of the Ninth International Conference on Offshore Mechanics and Arctic Engineering ... presented al ... Houston, Texas, February 18-23, 1990. Vol. 4. Arctic|polar technology. New York, American Society of Mechanical Engineers, 253-257.

MS received 14 April 1994 and accepted in revised form 14 December 1994 